\title{
ANTIQUITY
}

they have not wholly escaped attention. They are worthy of careful study and the official archaeologists should turn their energies upon them. That they are the work of a Bantu race is quite certain but their antiquity is perhaps a little greater than the 'experts' gave Captain Norton to believe ; I think they are probably a century or two earlier than Zimbabwe.

Mr R. S. Fairbridge, of Umtali, who has an unequalled knowledge of his own district, has written some articles to prove that the "slavepits' were used as tombs, or rather as cenotaphs. The theory is ingenious and deserves examination, but I prefer to regard these curious structures as habitations. Though simpler they are of the same generic class as the dwellings on the Niekerk site.

RANDAll MacIver.

\section{WINDMILL HILL, WILTSHIRE}

The greatest interest has been aroused in archaeological circles by the remarkable discoveries on Windmill Hill, near Avebury. Here the owners, Mr and Mrs Keiller, have been carrying out excavations for two seasons, with the assistance of Mr St. George Gray. The site was inhabited at a very early date in the prehistoric period; and the triple concentric ditches there, broken as they are by frequent causeways, have analogies in the Middle Rhine region. Mr Keiller allows the following forecast of his plans to be published. In 1927 digging will be carried out between 26 April and 28 May. Visitors will be allowed to visit the excavations on Saturday afternoons. The following year will be devoted to tabulating the results of the past three years' work, and to writing the first volume of the published account of the excavations. It is proposed to continue this method of publication every three or four years, and full arrangements have been made for the work to be carried on in the event of the death of any of the principals or any of the permanent staff. It is proposed thoroughly to excavate the entire site and any adjacent ground which might tend to throw light upon that site; but a certain portion of each distinctive part of the site will be left unexcavated and provision will be made for leaving these portions unexcavated for at least one century. Mr Keiller continues:- " This unusual arrangement is prompted by my realization of the inestimable advantage that it would have been to us of these days, had earlier excavators pursued this policy ; since it is merely futile to assume that future generations will not have further comparative data upon which to work, which will enable them doubtless to obtain more information from the excavation of a site than lies 


\section{NOTES AND NEWS}

within our power to-day. It will, moreover, give a future generation of archaeologists an opportunity of satisfying themselves that the reports of our work were reliable and accurate."

With regard to the excavations themselves Mr Keiller says :"The first year's work (1925) consisted of certain trial excavations of typical portions representing different features, e.g., Inner, Middle and Outer Ditch, and certain of the holes within the area. Last year we began upon the more definite line which would in future be followed, namely, excavating from causeway to causeway in any section which was undertaken. The next year's work (1927) will be the continuation of the first year's work upon the lines of the second year's work, that is to say, those sections in which diggings were made the first year will be completely excavated this year from causeway to causeway in each case, and the causeways themselves will be exposed."

Archaeologists will follow the work on this most important site with the greatest interest.

\section{FLINTS AND "FOOD-GATHERERS"}

Considerable success has attended the second year's excavations at Lower Halstow, near the mouth of the Medway, in Kent, of a series of Stone Age hearths; and it is now possible to group the finds as follows :-

(I) Types resembling forms of the Upper Palaeolithic period, including the graver.

(2) Microliths and quasi-microliths.

(3) Picks, pick-planes, axes, adzes and tranchets.

The adze is by far the most numerously represented.

A parallel industry may be cited as occurring on the west coast of Norway between Bergen and Trondhjem. The artifacts there recovered fall under the same grouping as set out above. The graver which occurs plentifully is not represented in the Shell Mounds of Denmark. Typologically, the Norwegian coastal industry is anterior to that of the Kitchen Midden period of Denmark; and geological evidence establishes the fact that these Norwegian sites were flourishing contemporaneously with the Magdalenian phase of Central Europe.

If the typological classification of the Upper Palaeolithic and Azilian-Tardenoisian cultures of Central Europe is correct, and if the Norwegian geological evidence is sound, then it is abundantly clear that the industries located on the Norwegian coastal sites and at Lower Halstow must be widely separated in point of time. J.P.T. BuRCHELL. 